\title{
Effect of Sintering Time and Reinforcements on Density, Hardness of Al/CNT-FA Composites
}

\author{
Sunil Kumar Shetty, Udaya
}

\begin{abstract}
CNT) and differing wt\% of Fly particles (FA) have been carried out to create Al/CNT-FA composites via the use of powder metallurgy which incorporates powder blending, compaction and sintering technique. This exam was essentially centered around to the development of aluminium(Al) steel framework composites $(M M C)$ and to contemplate the effect fortifications and sintering time on hardness and thickness houses. It modified into located that because the FA wt\% elevated,there has been noteworthy increment in thickness, hardness, up as far as viable (eight wt\%) beyond which it diminishes. The enlargement in sintering time furthermore had constructive very last outcomes on thickness and hardness houses. The floor morphology emerge as examined making use of checking electron magnifying lens to dissect the motion of fortifications. It modified into found that fortifications have been very a great deal scattered and furthermore refinement of the grains passed off as the sintering time turned into stepped forward.
\end{abstract}

Report phrases: Carbon nanotubes, steel framework composites,, Powder metallurgy, Scanning electron magnifying lens.

\section{INTRODUCTION}

Composite is large constructing material because of its novel property over unadulterated steel. As of late, composite substances have turn out to be extensive attention as contrasted and solid substances due to the upgraded mechanical homes, for example, firmness, durability and encompassing and immoderate temperature exceptional. because of their advanced presentation and reduce in weight with the aid of manner of 20-1/2 of of, composite substances have have become out to be basic designing materials and gotten more noteworthy attention in automobile, athletic machine, satellite tv for computer section, aviation, home machines and marine companies [1]. Fly debris (FA) particles are conceivably applied as fortifications in MMCs, due to their low thickness low-thickness and accessible requiring little to no strive and in large amounts as an unused aspect-effect in power developing devices. It turned into located that fly particles viably improves retaining among the framework and assist and builds hardness and wears obstruction of Al composite [2]-[3]. Carbon nanotube (CNT) has been pulling in high-quality hobby for its exceptional mechanical and conductive houses. From the literary works it very well may be inferred that CNTs as fortification improves mechanical and heat homes of metallic framework

Revised Version Manuscript Received on 10, September 2019.

Sunil Kumar Shetty, Assistant Professor, Mechanical Engineering Department, NMAM Institute of Technology, Nitte, India.(Email: sunilkumarshetty@nitte.edu.in)

Udaya, Associate Professor, Mechanical Engineering Department, NMAM Institute of Technology, Nitte, India.(Email: udaya_d@nitte.edu.in). composites and may be efficaciously utilized for some excessive top notch and auxiliary applications [4]-[7]. utilising CNTs in the aluminum framework is a number one check due to the trouble associated with the interfacial reaction amongst $\mathrm{CNTs}$ and $\mathrm{Al}$ grids, and inadequate introduction way. in this exam development of a metal lattice composite (MMC) making use of fly debris and CNT as a fortification and $\mathrm{Al}$ as network had been explored. Hardness, thickness miniaturized scale auxiliary exam of the composites modified into researched. The effect of sintering time and fortifications modified into exhibited and cited.

\section{EXPERIMENTAL APPROACH}

Thirty grams of $\mathrm{Al}$ powder implemented as framework material $(99.7 \%$ unadulterated, mean length $50 \mu \mathrm{m}$. Thickness $2.7 \mathrm{~g} / \mathrm{cm} 3$ ) and zero.five wt\% multi-divider carbon nanotubes (outdoor distance throughout 10-15 nm, inward width 2-6 nm, length-0.1-10 $\mu \mathrm{m}$, thickness $2.1 \mathrm{~g} / \mathrm{cm} 3$, agency, Chengdu synthetic concoctions Co. Ltd China) and 4, 8 and sixteen wt.\% of fly particles (endorse length 9.229 $\mu \mathrm{m}$, thickness 1 .seventy six $\mathrm{g} / \mathrm{cm} 3$ ) were carried out as fortifications. The mixture have been set in $250 \mathrm{ml}$ treated metal blending boxes containing hardened metal balls (eight $\mathrm{mm}$ width) giving a ball-to-powder weight share of eight:1. The boxes at that issue fomented using a planetary ball production unit at $250 \mathrm{rpm}$ for, $2 \mathrm{hr}$ processing time. $3 \mathrm{wt} . \%$ of methanol have been included as a manner manipulate operator a fantastic manner to lessen cold welding of the $\mathrm{Al}$ particles and furthermore to keep away from powders adhering to the balls and area dividers. Fig. 1 demonstrates the ball processing mechanical assembly applied for the powder mixing. blended powders were cold compacted in a kick the bucket and plunger plans $(12 \mathrm{~mm}$ distance throughout) at $285 \mathrm{MPa}$ weight. Compacted billets of $12 \mathrm{~mm}$ size and $25 \mathrm{~mm}$ stature had been sintered at $500{ }^{\circ} \mathrm{C}$ for 1,3 and $6 \mathrm{hrs}$ [9]. determine 2 demonstrates the artificial composite example. The hypothetical and trial thickness homes of Al/CNT-FA composites had been researched thru guiding principle of blends and Archimedes rule in my opinion, allude to (1) and (2).

$$
\begin{aligned}
& \rho_{c t}=V_{A l} \rho_{A l}+V_{F A} \rho_{F A}+V_{C N T} \rho_{C N T} \\
& \rho_{c}=\frac{m}{m-m_{1}} * \rho_{w}
\end{aligned}
$$

where, $\rho_{c t}=$ Theoretical density of composite in $\mathrm{g} / \mathrm{cc}$.

$\rho_{A l}, \rho_{F A}, \rho_{C N T}=$ Density of Al, FA, CNT respectively in $\mathrm{g} / \mathrm{cc}$. 


\section{EFFECT OF SINTERING TIME AND REINFORCEMENTS ON DENSITY, HARDNESS OF AL/CNT-FA \\ COMPOSITES}

$V_{A l}, V_{F A}, V_{C N T}=$ Volume fraction of $\mathrm{Al}, \mathrm{FA}, \mathrm{CNT}$ respectively. Equation (3) was used to calculate Relative density.

$$
\text { Relative density }=\left(\frac{\rho_{c}}{\rho_{c t}}\right) * 100
$$

The examples were checked for its hardness in Vickers hardness testing machine where precious stone indenter was pushed on the example surface of example utilizing a heap of $5 \mathrm{~kg}$ and the space framed was fit as a fiddle.

$$
\text { Vickers hardness number }(\mathrm{VHN})=\frac{1.8544 L}{d^{2}}
$$

Where $\mathrm{L}=$ load applied, $d^{2}=$ avg. length of diamond shaped pyramid.

The surface morphology was investigated by scanning electron microscope (SEM) to analyze the distribution of reinforcements.

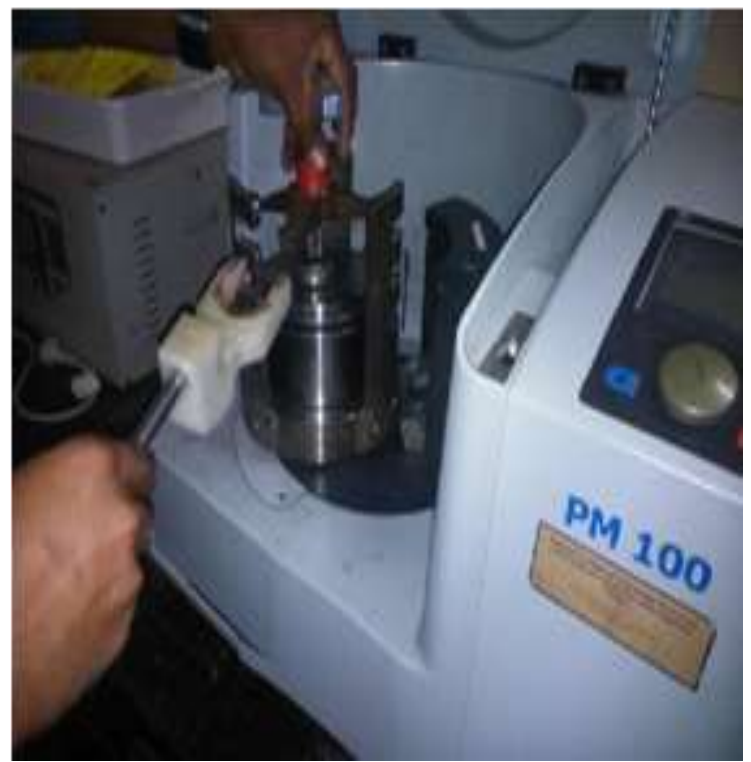

Fig. 1 Ball milling apparatus.

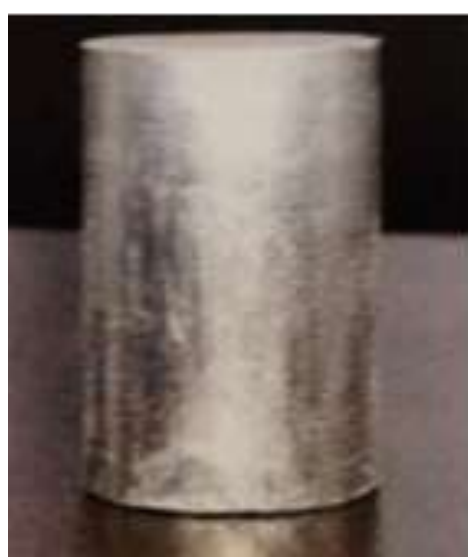

Fig. 2 Specimen within the wake of sintering

\section{OUTCOMES AND DISCUSSIONS}

A. Micro form have a have a look at:

The powders of FA MWCNT, Al crude substances were exclusively considered underneath filtering electron magnifying tool. FA with the spherical form having mean distance at some point of of $9.29 \mu \mathrm{m}$, MWCNTs having string like systems having cylindrical form with regular measurements $10-15 \mathrm{~nm}$ outside breadth, 2-6 $\mathrm{nm}$ interior width, and 0.1-10 $\mu \mathrm{m}$ long and $\mathrm{Al}$ debris with duration shifts from 7 tof $50 \mu \mathrm{m}$ personally was observed.

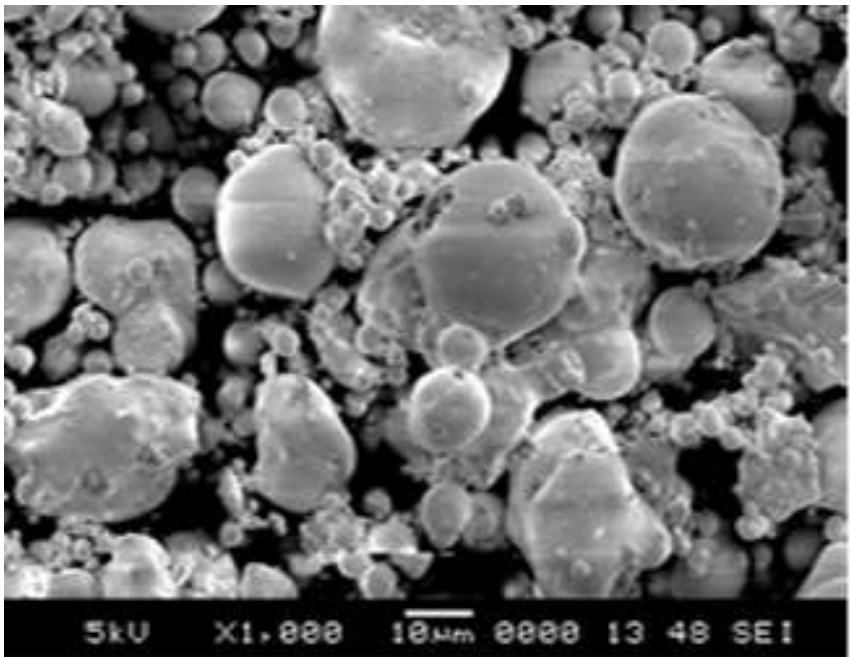

Fig. 3 SEM photos of FA powders.

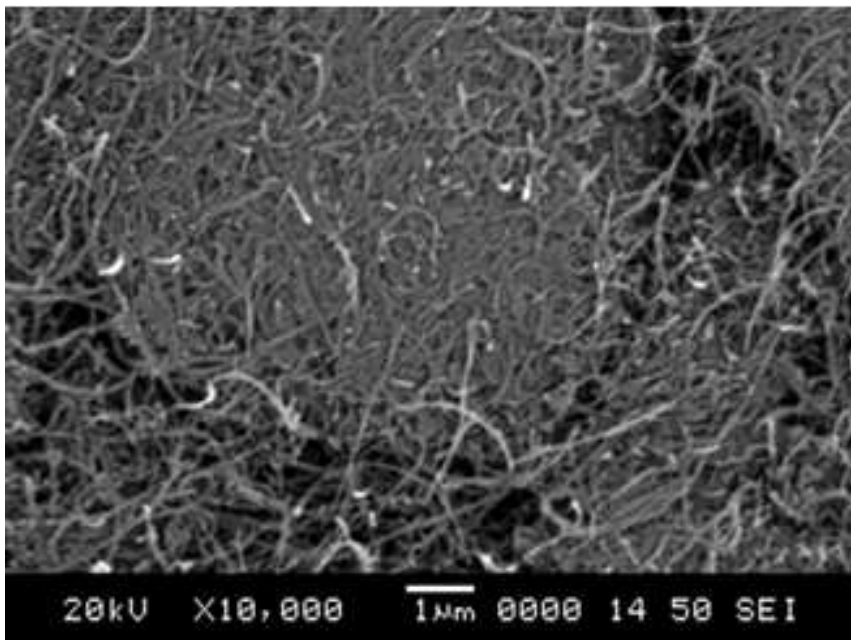

Fig. 4 SEM photos of MWCNTs powders

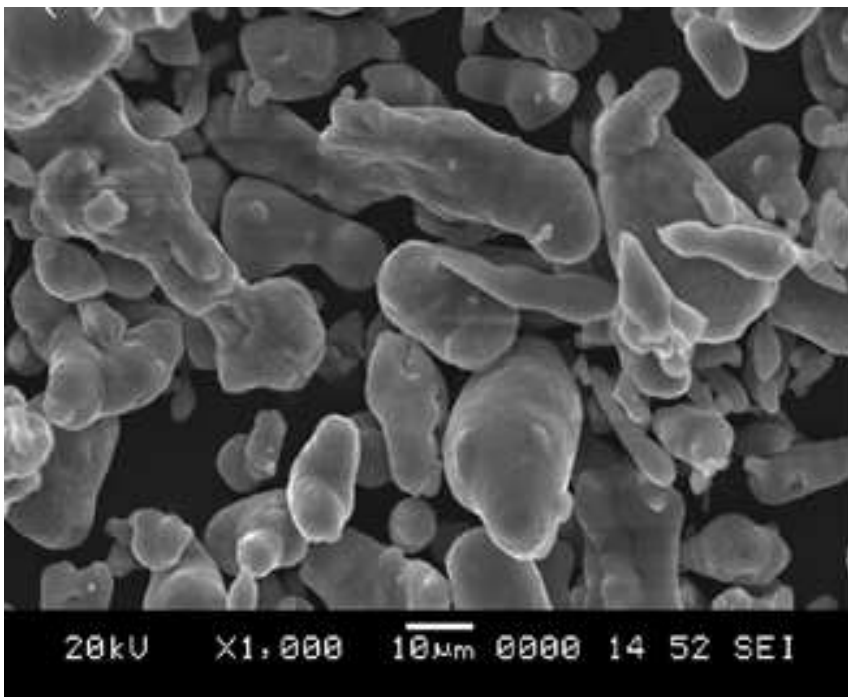

Fig. 5 SEM photos of pure Al powders.

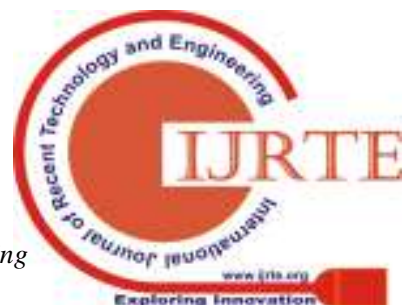




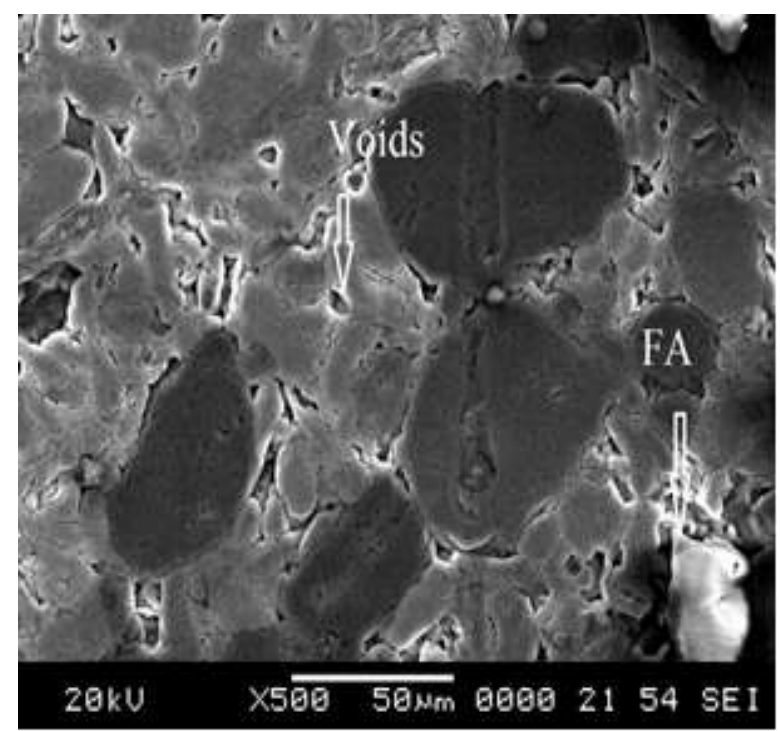

Fig. 6 SEM image of specimen after $1 \mathrm{hr}$ sintering

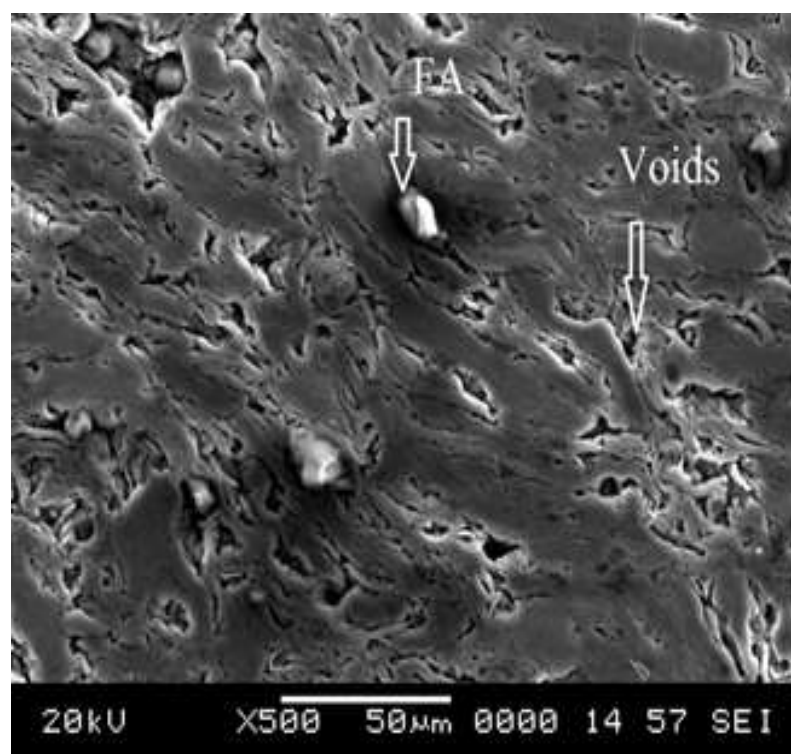

Fig. 7 SEM image of specimen after $3 \mathrm{hr}$. sintering

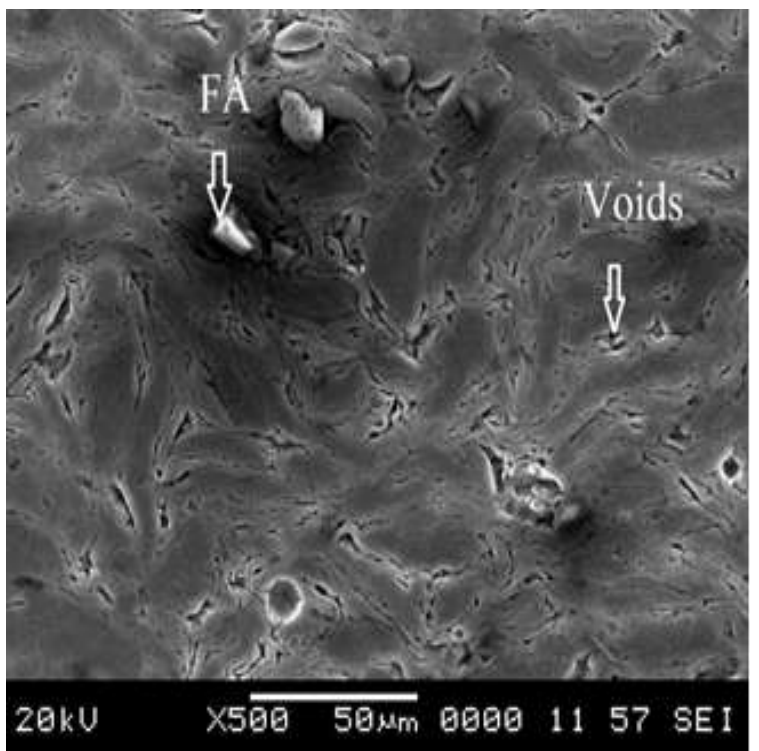

Fig. eight SEM image of example after $6 \mathrm{hr}$ sintering

SEM micrograph of the sintered composite had been seemed inside the Fig. 6,7 and 8. The composite glaringly uncovers that sound sintering with little porosity as sintering time changed into stepped forward with demonstrating a extremely good interfacial defensive between the FA-CNT debris and $\mathrm{Al}$ lattice substances. moreover it end up obvious that as sintering time builds porosity degree discounts. This come to be ascribed to the grain refinements at longer sintering sports.

\section{A. Mechanical homes}

Fig. eight and nine demonstrates the relative thickness and hardness of the various mixes of composites sintered for 1, 3 and six hours. It was clean that finest hardness seen as forty one.eighty one $\mathrm{HV}$ for 6 hours sintering time for the aggregate of 0.25 wt. \% CNT and eight wt.\% FA. Unadulterated $\mathrm{Al}$ hardness turned into visible as $22 \mathrm{HV}$. in the long run it thoroughly can be inferred that hardness is stepped forward by means of the usage of boom of fly debris and CNT to the unadulterated aluminum framework. Increment inside the homes emerge as ascribed to the tougher fortifying substances which were utilized inside the composites and also good adhesion between matrix and reinforcements.

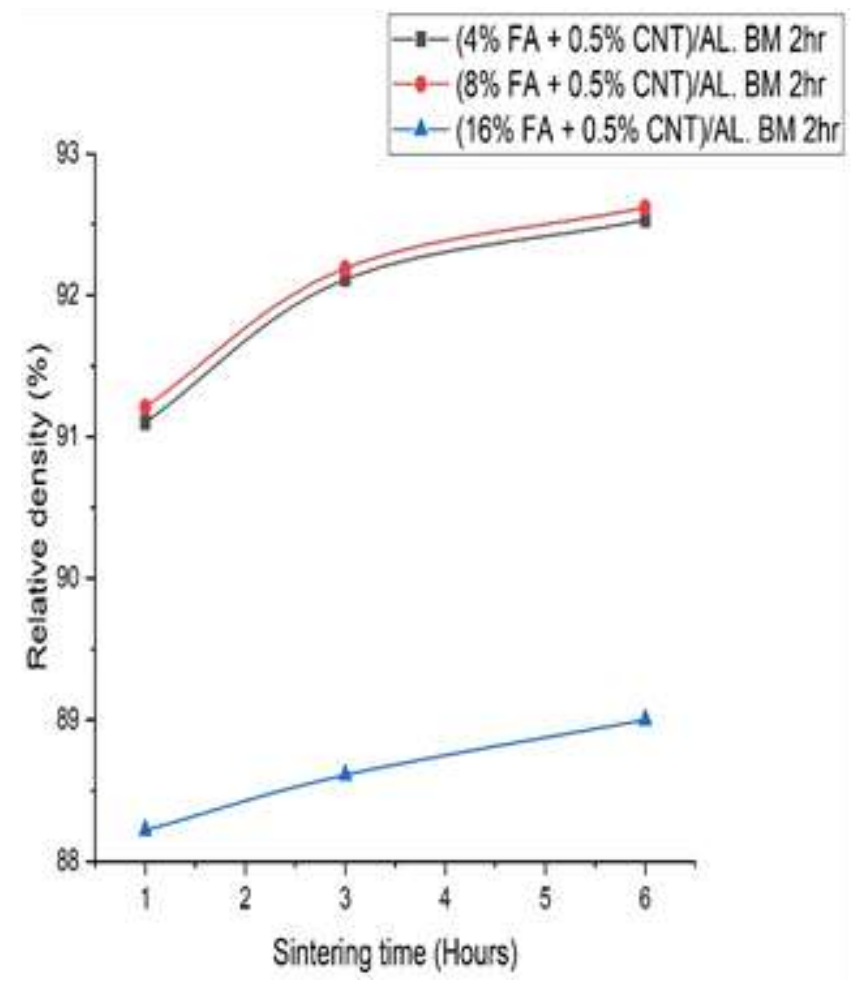

Fig. 9 Effect of Sintering time on Relative density 


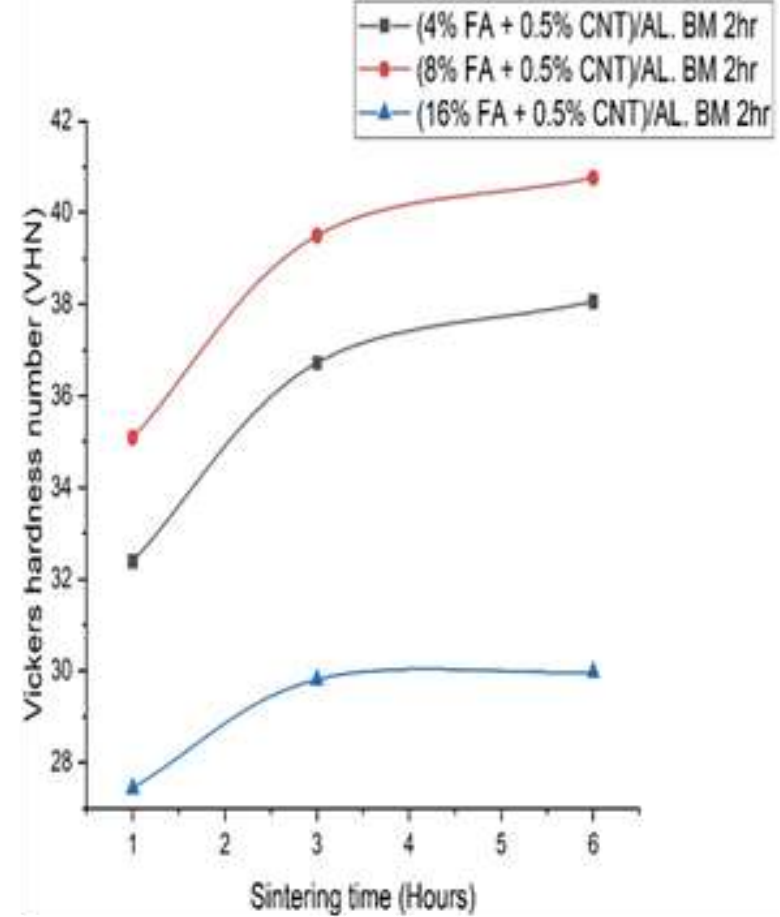

Fig. 10 impact of Sintering time on hardness

\section{A. impact of sintering time on relative thickness}

Fig. 9 demonstrates the impact of sintering time on relative thickness. it is clear that relative thickness increments with increment in sintering time. A maximum excessive 90 3.fifty three $\%$ relative thickness is watched for 6 hours of sintering time. this may be ascribed to the grain refinement takes area lessening the porosity degree [8].

\section{B. impact of sintering time on hardness}

Fig. 10 demonstrates the impact of sintering time on hardness of the composite. it's far apparent that hardness multiplied with increment in sintering time. Hardness of 41.eighty one $\mathrm{HV}$ is watched for the composite sintered at 6 hours sintering. This gradual effect might be because of the increasingly more grip of $\mathrm{Al}$ framework on strengthening material as sintering time increments. in this manner, robust bond among manual and lattice effects stepped forward hardness and lots a great deal much less porosity [8]..

C.effect of assist content material cloth on relative thickness

The impact of Fly particles at the relative thickness is seemed in Fig nine. It thoroughly can be visible that as weight $\%$ of Fly debris expands relative thickness of the instance diminishes. this may be credited to the prolonged improvement of circle urgent of FA molecule and the powerlessness of $\mathrm{Al}$ particles to diffuse into voids [8].

\section{D.effect of fortification substance on hardness}

Fig. 10 moreover demonstrates the effect of Fly debris at the hardness. Hardness definitely well worth seems, by way of all money owed, to be accelerated up to 8 wt. \% of Fly debris and commenced out diminishing over that. This underlying augmentation in VHN might be due to FA being similarly difficult cloth, enlargement of this positive to offer higher hardness in $\mathrm{Al}$ composite. The reason in the returned of decrement of hardness over 8 wt. \% of FA have grow to be due to expanded porosity [8].

\section{GIVE UP}

Trial examination introduced approximately the accompanying ends

- Powder metallurgy taken into consideration one in every of the ideal approach to create CNT and FA fortified aluminum composites.

- The aftereffects of the SEM pics indicated well scattering of the fortifications and refinement of grains for longer sintering occasions for the composites.

- The relative thickness of ninety 3 .Fifty $3 \%$ changed into watched for the composites for $6 \mathrm{hr}$ sintering time.

- increase in fly debris substance builds hardness up to eight wt.\% past that hardness diminishes.

- A most immoderate hardness forty one.80 one HV have become watched for the composites as in opposition to 22 $\mathrm{HV}$ for unadulterated $\mathrm{Al}$ showing improvement within the properties with the aid of the incorporation of CNTs and FA to the unadulterated $\mathrm{Al}$.

\section{REFERENCES}

1. Rohatgi P.k,Weiss D, and Gupta Nikhil, programs of Fly Ash in Synthesizing Low-fee MMCs for automobile and excellent programs, magazine of the Minerals, Metals and materials Society, vol fifty eight,(2006): pp seventy one-76

2. M. Ramachandra, adequate. Radhakrishna, impact of manual of fly debris on sliding placed on, slurry erosive placed on and negative conduct of aluminum community composite" placed on 262 (2007) pp.1450-1462

3. Sudarshan and Surappa, M.exact sufficient. (2008), "Dry sliding placed on of fly debris molecule strengthened A356 Al composites", positioned on, vol.265, pp.349-360.

4. T. Laha, Y. Chen, D. Lahiri, A. Agarwal, Tensile houses of carbon nanotube reinforced aluminum nanocomposite created thru plasma splash framing Composites: detail A 40 (2009) 589-594

5. A.M.ok. Esawi, k. Morsi, A. Sayed, A. Abdel Gawad, P. Borah, Fabrication and residences of scattered carbon nanotube-aluminum composites substances era and Engineering the huge apple, 1979, A 508 (2009) $167-$ $173 n$,

6. S.R.Bakshi,D.Lahiri and A. Agarwal Carbon nano cylinder strengthened steel community composites-a survey global substances critiques 2010 vol 55 \#1 pp. 45 -sixty 4

7. Rupesh Khare, Suryasarathi Bose "Carbon Nanotube based completely Composites-A have a look at mag of Minerals and materials Characterization and Engineering, vol. four, No.1, pp 31-forty six, 2005

8. R. Q. Guo, P. adequate. Rohatgi," steering of aluminumfly debris particulatecomposite via powder metallurgy method", magazine of substances era three 2 (1997) pp.3971-3974

9. Udaya, Dr. lower Fernandes "impact of fly particles and ball processing time on CNT-FA fortified Aluminum framework pass breed composites", Mater. Res. express https://doi.Org/10.1088/2053-1591/ab1e20. 


\section{AUTHORS PROFILE}

Sunil Kumar Shetty, BE, MTech(Design) cuurrently pursuing his Ph.D. He has published and presented many papers in conferences and Jounals . Life Member of Indian Society for Technical education, Indian Welding Society, Indian Society of Mechanical Engineers

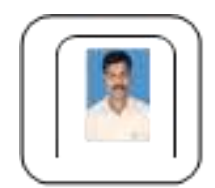

Udaya, B.E, M.Tech, cuurrently doing Ph.D in composite materials. He published papers in Material science forum, Material research express, ICETE 2018, ICAMPS 2018 conferences. Life Member of Indian Society for Technical education, Indian Welding Society, Indian Society of systems for Science and Engineering. 